\title{
Advanced scope of Korean oral and maxillofacial surgery
}

\author{
Young-Kyun Kim \\ Department of Oral and Maxillofacial Surgery, Section of Dentistry, \\ Seoul National University Bundang Hospital, Seongnam, Korea
}

The development of oral and maxillofacial surgery in Korea has been driven by our senior scholars who established the extensive realms only with their dentist licenses, competing with the other medical fields. In Europe and USA, doctors with double licenses of M.D. and D.D.S. have researched the field of oral and maxillofacial surgery, but typical countries where clinical experiences and basic research related to oral and maxillofacial surgery are actively conducted only with a dentist's license are Korea and Japan. The theses submitted to Journal of the Korean Association of Oral and Maxillofacial Surgeons (J Korean Assoc Oral Maxillofac Surg) have been original articles and case reports related to oncology \& reconstructive surgery, craniomaxillofacial trauma, craniomaxillofacial deformity, dental implantology, dentoalveolar surgery, anesthesia, temporomandibular disorder, and orofacial pain. Moreover, basic research articles on biomaterials such as bone graft material have been published from a long time ago; recently, theses on tissue engineering are increasingly published. For your reference, Journal of Oral and Maxillofacial Surgery (J Oral Maxillofac Surg) published in the USA carries theses on dentoalveolar surgery, facial injuries and deformities, temporomandibular joint (TMJ) disorders, oral cancer, jaw reconstruction, anesthesia and analgesia, specifics on new instruments, and diagnostic equipment and modern therapeutic drugs and devices ${ }^{1}$. The International Journal of Oral \& Maxillofacial Surgery is one of the world's leading journals in oral and maxillofacial surgery.

The Journal is divided into sections, ensuring that every aspect of oral and maxillofacial surgery is covered fully through a range of invited review articles, leading clinical and research articles, technical notes, abstracts, case reports, etc. Sections include congenital and craniofacial deformities, orthognathic surgery/aesthetic facial surgery, trauma, TMJ disorders, head and neck oncology, reconstructive surgery, implantology/dentoalveolar surgery, clinical pathology, oral medicine, research, and emerging technologies ${ }^{2}$.

The editorial board of $J$ Korean Assoc Oral Maxillofac Surg shall further widen the scientific scope in Korean oral and maxillofacial surgery focusing on the following items and continue to make efforts for the internationalization of the journal ${ }^{3}$ :

1. Including the review articles of eminent scholars at home and abroad

2. Open access to the journal

3. Registration of database at home and abroad

4. English proofreading

5. Training for editors, authors, and reviewers

6. Modifying the elements of the journal and submission regulation

7. Improvement of impact factor

8. Reinforcement of regulation for research ethics

9. Establishing strict and fast review system

\section{References}

1. Journal of Oral and Maxillifacial Surgery. Available from: http:// www.joms.org/home.

2. International Journal of Oral Maxillofacial Surgery. Available from: http://www.ijoms.com/aims

3. Huh S. Is my journal eligible to be indexed in international databases? 3rd ed. Seoul: XMLARCHIVE; 2009. DOI:10.5082/ Xmlarchive.2010.1 